\title{
Simulation of Heat and Mass Transfer of Cut Tobacco in a Batch Rotary Dryer by Multi-Objective Optimization *
}

\author{
by \\ Feng Huang ${ }^{1,2}$, Nan Deng ${ }^{1}$, Qiaoling Li $^{3}$, Bin Li ${ }^{1}$, Ruilin Hu ${ }^{1}$, Miao Liang ${ }^{1}$, Dengshan Luo ${ }^{1}$, and Le Wang ${ }^{1}$ \\ ${ }^{1}$ Zhengzhou Tobacco Research Institute of CNTC, Zhengzhou 450001, P.R. China \\ 2 School of Energy and Environment, Southeast University, Nanjing 210096, P.R. China \\ 3 China Tobacco Fujian Industrial Co. Ltd., Xiamen 361022, P.R. China
}

\section{SUMMARY}

To simulate the drying process of cut tobacco in a batch rotary dryer, six different models of equilibrium moisture content were selected to calculate the driving force of mass transfer, and a mathematical model of heat and mass transfer was numerically solved. The multi-objective nonlinear problem of heat and mass transfer coefficients was optimized by employing a weight factor. The simulation results showed that the weight factor $r$ was an important parameter for fitting results of moisture content and temperature. The model evaluation indices almost reached their minimal values with $r$ at 0.1 . For all the six equilibrium/classic models the fit was better for moisture content than for temperature. One model (M-HEN/C) was superior to other equilibrium/classic models and the REA (reaction engineering approach) model. This study aims for an understanding of heat and mass transfer in the tobacco drying process, and provides a theoretical framework to support the prediction of temperature and moisture in various drying situations. [Beitr. Tabakforsch. Int. 29 (2020) 145-155]

\section{KEY WORDS:}

Cut tobacco; drying; heat and mass transfer; equilibrium moisture content; multi-objective optimization

\section{ZUSAMMENFASSUNG}

Zur Simulation des Trocknungsprozesses bei Schnitttabak im Trommeltrockner im Chargenbetrieb wurden sechs verschiedene Modelle des hygroskopischen Gleichgewichts zur Berechnung der Antriebskraft beim Massetransport ausgewählt. Zudem wurde ein mathematisches Modell des Wärme- und Massetransports numerisch gelöst. Das multifaktorielle, nichtlineare Problem der Wärme- und Massetransportkoeffizienten wurde durch die Anwendung eines Gewichtungsfaktors optimiert. Aus den Simulationsergebnissen ging hervor, dass der Gewichtungsfaktor $r$ ein wichtiger Parameter bei der Anpassung der Ergebnisse für Feuchtigkeitsgehalt und Temperatur ist. In der Modellevaluation erreichten die Indizes mit $r$ bei 0,1 beinahe ihre Minimalwerte. Bei allen sechs Gleichgewichtsmodellen / klassischen Modellen war die Anpassung beim Feuchtigkeitsgehalt besser als bei der Temperatur. Ein Modell (MHEN/C) war anderen Gleichgewichtsmodellen/ klassischen Modellen sowie dem REA-Modell (reaction-engineering approach / Reaktionstechnikansatz) überlegen. Das Ziel der vorliegenden Studie ist ein tieferes Verständnis des Wärmeund Massetransports im Tabaktrocknungsprozess sowie die Schaffung eines theoretischen Rahmens zur besseren Prognose von Temperatur und Feuchtigkeit in verschiedenen Trocknungssituationen. [Beitr. Tabakforsch. Int. 29 (2020) 145-155]

*Received: $9^{\text {th }}$ April 2020 - accepted: $9^{\text {th }}$ November 2020 


\section{RESUME}

Dans le cadre d'une simulation du processus de séchage du tabac haché à l'intérieur d'un sécheur discontinu à tambour rotatif, six différentes modélisations de l'équilibre hygrométrique furent sélectionnées afin de calculer la force motrice du transfert de masse et un modèle mathématique de transfert de chaleur et de masse fut numériquement résolu. Le problème non-linéaire à objectifs multiples des coefficients de transfert de chaleur et de masse fut optimisé à l'aide d'un facteur de pondération. Les résultats de la simulation révélèrent que le facteur de pondération $r$ était un paramètre important de mise en relation des résultats de la teneur en humidité et de la température. Les indices d'évaluation des modèles atteignirent presque leurs minima à une valeur $r$ de 0,1 . Sur toutes les six modélisations équilibre/classique, la correspondance fut meilleure pour la teneur en humidité que pour la température. Un modèle (MHEN/C) supplanta les autres modèles équilibre/classique et le modèle REA (reaction engineering approach / approche fondée sur l'ingénierie des réactions). La présente étude entend approfondir la compréhension du transfert de masse et de chaleur lors du processus de séchage du tabac et propose un cadre théorique en guise d'appui aux prédictions de température et d'humidité dans diverses conditions de séchage. [Beitr. Tabakforsch. Int. 29 (2020) 145-155]

\section{INTRODUCTION}

Drying as a process of removing moisture has been widely used in different kinds of biomass treatments, such as with biofuels (1), fruits and vegetables (2), milk (3-4), tea (5) and tobacco (6). Distinct dryers were developed and applied for biomass-drying based on a variety of treatment purposes. Among these dryers were pneumatic conveying dryers (7), tunnel dryers (8), conveyor belt dryers (9), fixed-bed dryers (10), spout-fluidized-bed dryers (11) and rotary dryers. Among them, the rotary dryer is an effective equipment used in the tobacco industry for drying cut tobacco. In a rotary dryer, cut tobacco particles are moved, exposing them to hot air and the hot walls of the dryer, thus achieving a better drying efficiency. The physical and chemical properties of cut tobacco could be improved by optimizing the treatment conditions, such as wall temperature, air temperature, air flow rate, air humidity, and initial water content. However, the study of the detailed drying mechanisms of cut tobacco is difficult because of the complex heat and mass transfer between the two-phase flow occurring in a rotary dryer (13-15).

To investigate the drying process in a rotary dryer, it is common to build mathematical models on the basis of experiments. Many empirical and semi-empirical models have been studied by several researchers such as models of NeWTON et al. (16), PAGE et al. (17), HENDERSON and PABIS (18), MENGES and ERTEKIN (19), Midilli et al. (20) and HII et al. (21). These models lack clear physical interpretation, so they could not be employed over a wide range of drying conditions. They also could not predict the surface temperature of the material to be dried because only the moisture content was considered. Many researchers sought mathematical models coupled with heat and mass transfer to describe the evolution of both moisture content and temperature during the drying process. XU and PANG developed a mathematical model to simulate the drying of wooden chips in a rotary dryer (22). Gu et al. studied the influence of moisture content and humidity on flexible filamentous particles in a counter-current cascading rotary dryer (23). ZHU et al. simulated the evolution of cut tobacco temperature and moisture by a developed heat and mass transfer model (24). These models based on the classic theory of heat and mass transfer can be found in a number of articles and books on drying technology. However, these models were not suitable to solve the problem of heat and mass transfer in a rotary drying process due to their lack of adaptable parameters. In addition, the reaction engineering approach (REA) is seen as a new approach to simulate the drying process of single particles and thin-layer materials, which is proposed by CHEN and his coworkers (25-27). This method considered the drying process as a chemical reaction, and the kinetic parameters of the drying process were obtained through experiments. Li et al. designed a batch rotary dryer to study the drying characteristic of cut tobacco (28). The REA model was well validated by experimental data at various wall temperatures, which illustrated that the REA model could well simulate the drying characteristics of cut tobacco. However, the calculation process of the REA model was complicated. It was difficult to evaluate whether the heat transfer coefficient or the mass transfer coefficient is optimal.

This study uses experimental data from Li et al. (28), it focuses on the development of a simpler and more easily comparable heat and mass transfer model to simulate the drying process of cut tobacco in a batch rotary dryer. Six different models of equilibrium moisture content were selected to calculate the driving force of mass transfer, and a mathematical model of heat and mass transfer was numerically solved by using multi-objective nonlinear optimization. The multi-objective nonlinear problem of heat and mass transfer coefficients was optimized by employing a weight factor. Moreover, two kinds of evaluation methods were used to investigate the fitting results of different equilibrium/classic models.

\section{MODEL DEVELOPMENT}

Cut tobacco from the top leaves with a moisture content of $22.5 \pm 0.1 \%$ (wet basis) was used in this study (28). The drying experiments were carried out in a batch rotary dryer (Xiamen Yingde Industry and Trade Co. Ltd., Fujian, China). The temperature of the inlet air was tested at five levels, $338.15 \mathrm{~K}, 358.15 \mathrm{~K}, 378.15 \mathrm{~K}, 398.15 \mathrm{~K}$ and $418.15 \mathrm{~K}$ respectively, while the average velocity of the air flow was kept at $0.067 \mathrm{~ms}^{-1}$. During the drying process, the sampling interval was set from $30 \mathrm{~s}$ to $300 \mathrm{~s}$ as the drying process proceeded.

\subsection{Heat and mass transfer model}

In order to simulate the mass transfer, the two-film theory was adopted (29-30). We assumed that on the surface of cut tobacco particles, there existed a film of wet air, which 
kept a balance between water vapor density in the gas layer and moisture content in the cut tobacco particles. We also assumed that the convective mass transfer occurs as the primary process during drying, and the diffusion effect among cut tobacco particles was insignificant. Therefore, the mass transfer flux could be written as the product of the convective mass transfer coefficient and the driving force of mass transfer, which is expressed as the difference of water vapor density between the hot air and the gas film on the surface of the cut tobacco. The drying process of cut tobacco can be described as the following differential equation [1].

$\frac{d X}{d t}=h_{m} A_{m}\left(\rho_{b}-\rho_{e}\right)$

where $X$ is the moisture content of cut tobacco on a dry basis, $h_{m} A_{m}=k_{m}$ is the product of the convective mass transfer coefficient $h_{m}$ and the mass transfer surface area $A_{m}, \rho_{b}$ is water vapor density in an equilibrium state of the gas film. Subscript $b$ denotes the hot air and $e$ denotes equilibrium zone.

According to the ANTOINE equation (31), the vapor pressure in hot air and in a film can be expressed as the product of the saturated vapor pressure and the relative humidity, which are given as equation [2]:

$$
p_{i}=1.1939 \times 10^{10} \exp \left(-\frac{3826.36}{T_{i}-45.47}\right) R H_{i}, i=b, e
$$

where $\rho_{b}$ is the vapor pressure in hot air, $R H_{b}$ represents the humidity in hot gas, $T$ denotes the temperature of cut tobacco, $\rho_{e}$ is the vapor pressure in the gas film, and $R H_{e}$ represents the equilibrium humidity in the gas film.

In order to get the vapor density, the hot air in the rotary dryer is assumed to satisfy the ideal gas equation, and its temperature is equal to the wall temperature of the rotary dryer. The vapor density in hot air and the gas film are given as equation [3]:

$$
\begin{aligned}
& \rho_{i}=\frac{p_{i} M_{w}}{R T_{i}}= \\
& \frac{1.1939 \times 10^{10} \exp \left(-\frac{3826.36}{T_{i}-45.47}\right) M_{w} R H_{i}}{R T_{i}}, i=b, e
\end{aligned}
$$

where $R$ is the universal gas constant, and $M_{w}$ is the molecular weight of water.

In above equations, the relative humidities of hot air $R H_{b}$ in each of the operation conditions are shown in Table 1.

\begin{tabular}{|c|c|c|}
\hline \multicolumn{2}{|c|}{ Drying conditions } & \multirow{2}{*}{$\begin{array}{l}\text { Tobacco equilibrium } \\
\text { moisture content }(\%\end{array}$} \\
\hline $\begin{array}{l}\text { Temperature } \\
(\mathrm{K})\end{array}$ & $\begin{array}{c}\text { Relative humidity } \\
(\%)\end{array}$ & \\
\hline 338.15 & 0.115 & 0.048 \\
\hline 358.15 & 0.050 & 0.035 \\
\hline 378.15 & 0.024 & 0.027 \\
\hline 398.15 & 0.012 & 0.022 \\
\hline 418.15 & 0.007 & 0.018 \\
\hline
\end{tabular}

Table 1. The drying conditions and their corresponding equilibrium moisture content in tobacco on dry basis $X_{e}(28)$.
In order to develop the mathematical model of heat and mass transfer, the equilibrium humidity of air $\left(R H_{\mathrm{e}}\right)$ on the surface of cut tobacco (the same as the equilibrium humidity in the gas film) at different conditions are required, the model was used to calculate the driving force of mass transfer. According to Table 1, the equilibrium moisture content model (EMC) was introduced to establish a relationship between equilibrium temperature and moisture content of cut tobacco and equilibrium humidity of the air. In this study, six popular models were chosen to study the relative humidity in an equilibrium state. The models were Henderson (32), Modified Henderson (33), Modified Oswin(34), Chung and Pfost (35), Modified ChungPFOST (36) and HALSEY (37). Each model not only could be used for moisture content as a function of relative humidity and temperature, but also for relative humidity as a function of moisture content and temperature. The six models are summarized in Table 2 (see page 148).

In Table $2 X_{\mathrm{e}}$ is the equilibrium moisture content of cut tobacco corresponding to the equilibrium state, $R H_{\mathrm{e}}$ is the equilibrium humidity of air (gas layer), $T$ is the temperature of cut tobacco. A, B and C are parameters of each model. On the other hand, the heat transfer equation of the drying process is simple to describe since the temperature change of cut tobacco can be attributed to two main factors. The one is convective heat transfer from the hot air, the other is endothermic vaporization of water during the drying of cut tobacco. According to the energy conservation equation, the general heat transfer equation based on the experimental date could be written as:

$$
\left(X C_{p, w}+C_{p, t}\right) \frac{d T}{d t}=h A_{m}\left(T_{b}-T\right)+\Delta H_{w} \frac{d X}{d t}
$$

where $T$ is the temperature of cut tobacco, $T_{b}$ is the bulk air temperature, $h A_{m}=k_{h}$ denotes the convective heat transfer coefficient combining with inseparable heat transfer area, $\Delta H_{w}$ is the latent heat of vaporization of water, $C_{p, w}$ is the specific heat capacity of the water and $C_{p, t}$ is the specific heat capacity of cut tobacco. In equation [4], the transfer of heat by conduction is neglected due to the fact that the particles of cut tobacco were fully subjected to the hot air in the rotary dryer, even in a packed state.

Since cut tobacco is a kind of irregular-shaped, elastic and compressed material and its particles contain a certain amount of water, the mass heat capacity of cut tobacco is complicated to express accurately. For simplification, the mass heat capacity of cut tobacco is assumed to be a linear combination of mass heat capacity of water and mass heat capacity of dry cut tobacco.

For the integrity of the heat transfer equation, the latent heat of vaporization $\left[\mathrm{J}^{\mathrm{kg}} \mathrm{kg}^{-1}\right]$ (38) and the specific heat capacity $\left[\mathrm{J}^{\mathrm{kg}} \mathrm{kg}^{-1} \cdot \mathrm{K}^{-1}\right]$ of water (39) are assumed as functions of cut tobacco temperature $(\mathrm{K})$, and they can be expressed as:

$$
\begin{aligned}
& \Delta H_{w}=2891833\left(1-\frac{T}{647.13}\right)^{0.321} \\
& C_{p, w}=1.459 \times 10^{-6} T^{4}-1.971 \times 10^{-3} T^{3}+ \\
& 1.005 \times T^{2}-228.7 T+23750
\end{aligned}
$$


Table 2. Mathematical models of equilibrium moisture content.

\begin{tabular}{|c|c|c|}
\hline Name of the model & & Equation \\
\hline HENDERSON & $(\mathrm{HEN})$ & $R H_{e}=1-\exp \left(-A T X_{e}^{B}\right)$ \\
\hline MODIFIED HENDERSON & $(\mathrm{M}-\mathrm{HEN})$ & $R H_{e}=1-\exp \left(-A(T+B) X_{e}^{1 / c}\right)$ \\
\hline MODIFIED OsWIN & $(\mathrm{M}-\mathrm{Osw})$ & $R H_{e}=\frac{1}{1+\left(\frac{A+B T}{X_{e}}\right)^{\frac{1}{c}}}$ \\
\hline ChUNG-PFOST & $(\mathrm{C}-\mathrm{P})$ & $R H_{e}=\exp \left(-\frac{A}{T} \exp \left(-B X_{e}\right)\right)$ \\
\hline MOdIFIED CHUNG-PFOST & $(\mathrm{M}-\mathrm{C}-\mathrm{P})$ & $R H_{e}=\exp \left(-\frac{A}{T+B} \exp \left(-C X_{e}\right)\right)$ \\
\hline HALSEY & (HAL) & $R H_{e}=\exp \left(-\frac{A}{T X_{e}^{B}}\right)$ \\
\hline
\end{tabular}

For simplification of the mathematical model the mass heat capacity $\left(\mathrm{J} \cdot \mathrm{kg}^{-1} \cdot \mathrm{K}^{-1}\right)(40)$ of cut tobacco remains unchanged with temperature, and is set to

$$
C_{p, t}=1.4286 \times 10^{3}
$$

In summary, the drying process of cut tobacco in a rotary dryer, is governed by both the mass transfer equation and the heat transfer process. The convective mass and heat transfer coefficients are the critical factors of the mathematical model, which are determined by the operating conditions such as inlet flow rate of hot air, the volume of cut tobacco and others. It is difficult to directly obtain accurate values of the two coefficients by independent experiments, because the heat transfer and mass transfer are coupled. However, they could be fitted by the temperature and moisture curves of cut tobacco simultaneously by an optimization method.

Besides the classic heat and mass transfer model, the reaction engineering approach (REA) is an application of chemical reaction engineering principles to simulate the drying process. The only difference between the classic model and REA model is the mass transfer equation, and the heat transfer equations of both models are the same. The mass transfer equation of the REA model is written as equation [8] (28):

$m_{t} \frac{d X}{d t}=-h_{m} A\left[\rho_{v, s a t}\left(T_{t}\right) \exp \left(-\frac{\Delta E_{v}}{R T_{t}}\right)-\rho_{v, b}\right]$

Herein, $m_{t}(\mathrm{~kg})$ is the mass of dried cut tobacco, $t$ is the drying time (s), $X\left(\mathrm{~kg} \cdot \mathrm{kg}^{-1}\right)$ is the cut tobacco's moisture content on dry basis, $h_{m}\left(\mathrm{~m} \cdot \mathrm{s}^{-1}\right)$ is the mass transfer coefficient, $A\left(\mathrm{~m}^{2}\right)$ is the surface area of cut tobacco for mass transfer, $\rho_{v, s a t}\left(\mathrm{~kg} \cdot \mathrm{m}^{-3}\right)$ is the saturated vapor concentration corresponding to the cut tobacco temperature $T_{t}(\mathrm{~K}), \rho_{v, b}\left(\mathrm{~kg} \cdot \mathrm{m}^{-3}\right)$ is the vapor concentration of bulk drying air, and $\Delta E_{v}\left(\mathrm{~J} \cdot \mathrm{mol}^{-1}\right)$ is the apparent addi- tional activation energy. More details of the REA model can be found in the literature (28). The simulation results of the REA model are also discussed in this study.

\subsection{Calculation method}

Our target is to find the optimal value of heat and mass transfer coefficients by fitting moisture content and temperature of cut tobacco to experimental data for all temperature conditions simultaneously. From the standpoint of mathematics, it is a multi-objective nonlinear optimization problem, which can be defined as:

$\operatorname{minimize}\left\{\begin{array}{l}f\left(h A_{m}, h_{m} A_{m}\right)=\sum_{j=1}^{M} \sum_{i=1}^{N}\left(\frac{X_{\mathbf{c a l}, i, j}-X_{\text {exp }, i, j}}{X_{\text {exp }, i, j}}\right)^{2} \\ g\left(h A_{m}, h_{m} A_{m}\right)=\sum_{j=1}^{M} \sum_{i=1}^{N}\left(\frac{T_{\text {cal }, i, j}-T_{\text {exp }, i, j}}{T_{\text {exp }, i, j}}\right)^{2}\end{array}\right.$

subject to $\left\{\begin{array}{l}\left(X_{\text {cal }} C_{p, w}+C_{p, t}\right) \frac{d T_{\text {cal }}}{d t}=h A_{m}\left(T_{b}-T_{\text {cal }}\right)+ \\ \Delta H_{w} \frac{d X_{\text {cal }}}{d t}, T_{\text {cal }}(0)=T_{\text {exp }}(0) \\ \frac{d X_{\text {cal }}}{d t}=h_{m} A_{m}\left(\rho_{b}-\rho_{e}\right), X_{\text {cal }}(0)=X_{\text {exp }}(0) \\ T_{b}=338.15,358.15,378.15,398.15,418.15\end{array}\right.$

where $M$ is the total number of experiments, $N$ indicates the total amount of data in each experiment, $X_{\text {cal }, i j}$ is the predicted value of moisture content, $\mathrm{X}_{\text {exp }, i, j}$ is the experimental value of moisture content, $T_{\text {cal }, i j}$ is the predicted value of tobacco temperature, $X_{\text {exp }, i, j}$ is the experimental value of tobacco temperature, the subscripts $i$ and $j$ are the number of data points on each trial and the number of test conditions, respectively.

In general, an optimal solution for a multi-objective optimization problem cannot be found because all the objectives usually cannot be achieved at the same time. However, the weighted sum is a popular approach to obtain a PARETO opti- 
mal solution (41-42).

In this method, the utilization of weight factor $r$ is to combine multi-objectives into a single objective. So, the final objective function of our optimization problem can be written as:

$$
\begin{aligned}
\operatorname{minimize} & \sum_{j=1}^{M} \sum_{i=1}^{N}\left(r \frac{X_{\mathrm{cal}, i, j}-X_{\text {exp }, i, j}}{X_{\exp , i, j}}\right)^{2}+ \\
& \sum_{j=1}^{M} \sum_{i=1}^{N}\left((1-r) \frac{T_{\mathrm{cal}, i, j}-T_{\text {exp }, i, j}}{T_{\exp , i, j}}\right)^{2}
\end{aligned}
$$

where $r$ is the weight factor varying from zero to one. In MATLAB a fourth-order RUNGE-KUTTA method was used to integrate the system of differential equations [1] and [4] and that the non-linear optimization problem was solved by an iterative algorithm. The multi-objective nonlinear problem of heat and mass transfer coefficients was optimized by employing the weight factor $r$.

\subsection{Model evaluation}

This is a multi-objective nonlinear optimization problem, which means that often there is no optimal solution. However, it is important for the evaluation of each objective for guiding practical work. The quality of the fitted curves was evaluated by using the Root Mean Square Error (RMSE) and the Mean Relative Deviation (MRD) (21, 43). The equation for RMSE and MRD can be written as:

$$
\begin{aligned}
& R M S E_{X}=\sqrt{\frac{\sum_{i=1}^{N}\left(X_{\mathrm{exp}, i}-X_{\mathrm{cal}, i}\right)^{2}}{N}, R M S E_{T}=\sqrt{\frac{\sum_{i=1}^{N}\left(T_{\mathrm{exp}, i}-T_{\mathrm{cal}, i}\right)^{2}}{N}}} \\
& R M S E_{\text {total }}=\sqrt{\frac{\sum_{i=1}^{N}\left(X_{\mathrm{exp}, i}-X_{\mathrm{cal}, j}\right)^{2}+\sum_{i=1}^{N}\left(T_{\mathrm{exp}, i}-T_{\mathrm{cal}, i}\right)^{2}}{2 N}} \\
& M R D_{X}=\frac{1}{N} \sum_{i=1}^{N} \frac{\left|X_{\mathrm{exp}, i}-X_{\mathrm{cal}, i}\right|}{X_{\mathrm{exp}, i}}, M R D_{T}=\frac{1}{N} \sum_{i=1}^{N} \frac{\left|T_{\mathrm{exp}, i}-T_{\mathrm{cal}, i}\right|}{T_{\mathrm{exp}, i}} \\
& M R D_{\text {total }}=\frac{M R D_{X}+M R D_{T}}{2}
\end{aligned}
$$

where the subscript $X$ represents moisture content, subscript $T$ is temperature and subscript total indicates moisture content and temperature together.

\section{RESULTS AND DISCUSSION}

\subsection{Fitting of EMC models}

The equilibrium moisture content model (EMC) provided the relationship between equilibrium moisture content, the temperature of the cut tobacco, and the ambient humidity. It was not only used to describe the isothermal adsorptiondesorption process but was also employed to characterize the non-isothermal process when the temperature difference between air and cut tobacco was not significant enough. Since the heat and mass transfer equations were coupled, the accurate prediction of the equilibrium humidity $\mathrm{RH}_{\mathrm{e}}$ not only affected the predicted moisture content of cut tobacco during the drying process but also influenced the predicted temperature on the tobacco surface.

Table 3 shows the estimated coefficients and effects of fitting six EMC models. When comparing the RMSE value, the models of MODIFIED HENDERSON and MODIFIED OSWIN shared the best value, those of HENDERSON model and MODIFIED CHUNG-PFost model were in the middle, and CHUNG-PFOST model had the least best fit. When comparing the MRD value, MODIFIED OsWIN model slightly outperformed the MODIFIED HENDERSON model. By combining the two evaluation methods, the results indicated that the MODIFIED OSWIN model was the best, and the Chung-PFost model was the worst.

Interestingly, these EMC models were previously only used below a temperature of $373.15 \mathrm{~K}$ (34), but all of the models still showed good effects on the simulation of the equilibrium drying state of cut tobacco in a more wider range of temperature conditions $(338.15 \mathrm{~K}-418.15 \mathrm{~K})$.

The result showed that they still had good applicability in high temperatures and low humidity drying conditions. Moreover, the effect of the EMC model on the simulation of the heat and mass transfer model needs to be confirmed further.

\subsection{The influence of factor $r$ on the fitting result}

Figure 1 shows the influence of weight factor $r$ on the simulation results of temperature and moisture content during cut tobacco drying. Due to the fact that the MoDIFIED HENDERSON (M-HEN) model gave the best result on fitting among the six EMC models, this model was selected. Comparing the calculated data with the experimental data, it can be seen that the weight factor $r$ had an obvious influence on the fitting results.

Table 3. Estimated coefficients and criteria for comparing EMC models for cut tobacco.

\begin{tabular}{l|c|c|c|c|cc}
\hline Parameter & HENDERSON & $\begin{array}{c}\text { MODIFIED } \\
\text { HENDERSON }\end{array}$ & MODIFIED OSWIN & CHUNG-PFOST & $\begin{array}{c}\text { MODIFIED } \\
\text { CHUNG-PFOST }\end{array}$ & HALSEY \\
\hline A & 3.5239 & -0.9313 & -0.0914 & 3397.00 & $1.63 \cdot 10^{5}$ & 22.6107 \\
B & 3.0239 & -516.0073 & 0.0006 & 32.1078 & $2.09 \cdot 10^{4}$ & 1.1462 \\
C & & 0.4210 & 0.4553 & & 26.4425 & 0.0015 \\
RMSE & 0.0010 & 0.0004 & 0.0004 & 0.0029 & 0.0018 \\
MRD & 0.0554 & 0.0255 & 0.0172 & 0.1751 & 0.0940 & 0.1052 \\
\hline
\end{tabular}



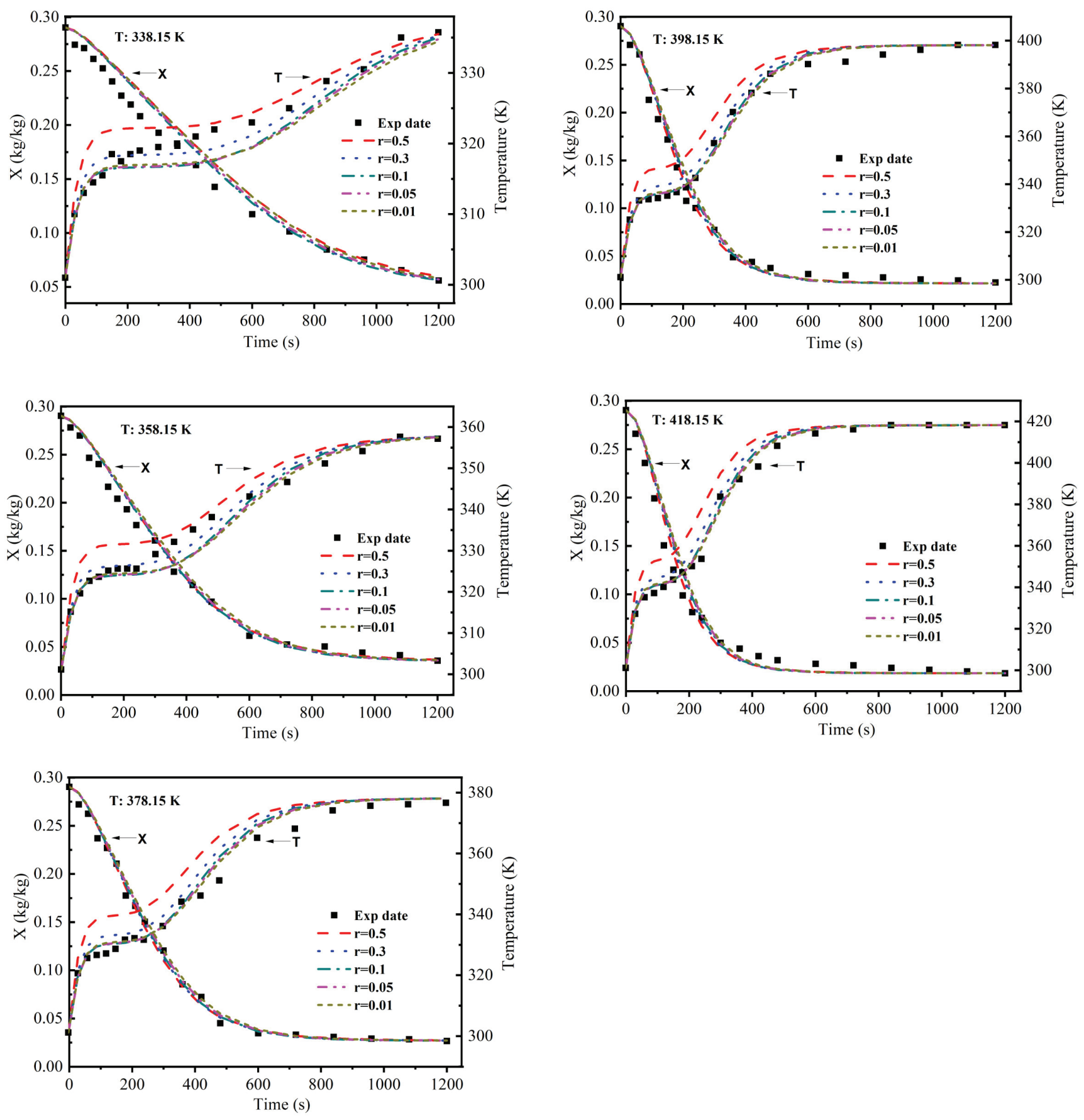

Figure 1. Comparison between experimental data and simulations given by M-HEN/Classic model at varying weight factor $r$ values.

With the decrease of weight factor $r$ in all drying situations, the fitting curves of water content were improving at first, then becoming worse, but the fitting curves of temperature were improving. When the weight factor $r$ was 0.1 , the simulated temperature was close to the experimental values in most conditions, especially at $378.15 \mathrm{~K}$ and at higher temperatures. While the weight factor $r$ was further reduced to 0.01 , the fitting quality for the temperature rose but slowly, but the fitting quality for the moisture content declined.

Figure 2 shows the total RMSE and MRD over the weight factor r. As it drops from 0.9 to 0.01 , the total RMSE gradually decreases at first, then accelerates and finally decreases slowly. The curve of RMSE shows an S-shaped trend as a whole. The reason that the RMSE mainly reflects the fitting results of the temperature data might be due to the magnitude of the temperature data being much higher than that of moisture content. 


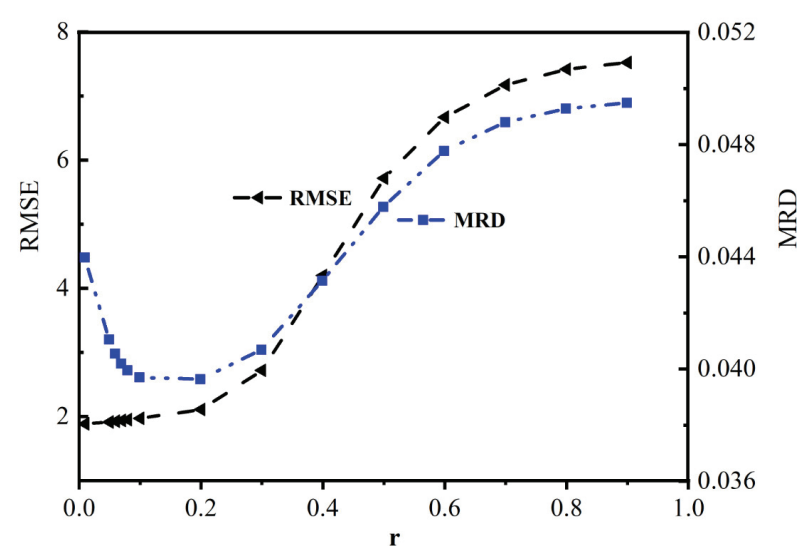

Figure 2. Comparison between RMSE and MRD at various weight factor $r$ values ranging from 0.9 to 0.01 . Model: M-HEN/Classic model.

It has turned out that the smaller the weight factor was, the better the fitting results of the temperature curves have proved. In dependency of $r$, the transformation of MRD values was different from that of the respective RMSE values. When the weight factor $r$ was 0.1 , the value of MRD was approaching a minimum. As the value of $r$ decreased from 0.1 to 0.01 , the MRD value began to increase significantly. Combining the two evaluation indices, the best fitting result was obtained when the weight factor $r$ was chosen to be 0.1 . Figure 3 shows the variation of mass transfer coefficient $k_{m}$ and heat transfer coefficient $k_{h}$ with respect to weight factor $\mathrm{r}$. With the decrease of $\mathrm{r}$ from 0.9 to 0.01 , the value of $k_{h}$ dropped slowly at first, then rose, and finally declined slowly. However, the value of $k_{m}$ steadily increased as the coefficient $\mathrm{r}$ decreased from 0.9 to 0.1 . When the weight factor $\mathrm{r}$ was at $0.1, k_{m}$ reached its maximum at $0.07 \mathrm{~m}^{3} \cdot \mathrm{kg}^{-1} \cdot \mathrm{s}^{-1}$, and $k_{h}$ is $31.4 \mathrm{~W} \cdot \mathrm{kg}^{-1} \cdot \mathrm{K}^{-1}$. These heat and mass transfer coefficients could also be considered as the optimal values.

\subsection{The influence of heat and mass transfer models}

Various models of heat and mass transfer were set up based on different EMC models as a driving force of mass transfer. Figure 4 shows the fitting curves of moisture content and temperature for all mathematical models in various drying conditions, where the weight factor $r$ was set to 0.1 . The fitting results of HEN/REA and equilibrium /C models were acceptable, where " $\mathrm{C}$ " following a model name indicates the use of the classical heat and mass transfer model. There were some differences between HEN/REA and classic models. The fitting results of the HEN/REA model were better in the lower temperature range from $338.15 \mathrm{~K}$ to $378.15 \mathrm{~K}$, but became worse when the drying temperature increased to $398.15 \mathrm{~K}$ and higher. The fitting of moisture content and temperature for the classic models were best at $378.15 \mathrm{~K}$. The larger the temperature difference from $378.15 \mathrm{~K}$, the least good fitting results of classic models were obtained. Comparing the temperature curves of HEN/REA and the classic models, the fitting of temperature of classic models was better than that of the HEN/REA model when the moisture content of cut tobacco was in the range of $9-15 \%$, but the HEN/REA model was better suited for a moisture content less than $5 \%$.

Figure 5 shows the total RMSE and MRD values of differ-

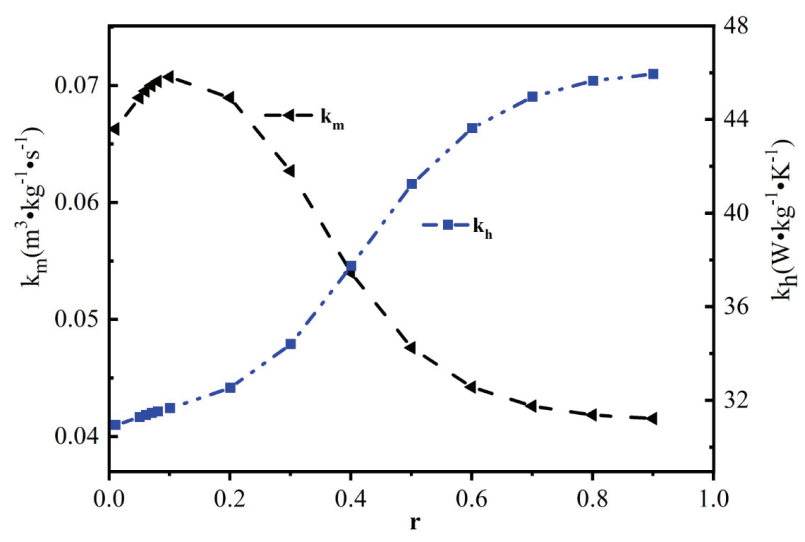

Figure 3. Coefficients of $\boldsymbol{k}_{m}$ and $\boldsymbol{k}_{h}$ at different weight factor $r$ values in the range of 0.9 to 0.01 . Model: M-HEN/Classic model.

ent models. The total RMSE contains the sum of the absolute fitting deviation of temperature and moisture. The results show that the deviation of $\mathrm{M}-\mathrm{Osw} / \mathrm{C}$ is the smallest, followed by the M-HEN/C model, and those of Hen/REA model are the largest. Since the absolute deviation of temperature was significantly higher than that of moisture, the total RMSE value was mainly affected by temperature. As mentioned above, the temperature fitting results of the HEN/REA model were inferior to those of classic models. Therefore, the total RMSE values of the classic models were relatively lower. To eliminate the influence of magnitude, the MRD value displayed better comparability for estimating the fit of each model. It was found that the total MRD value of the M-HEN/C model was the lowest, while those of $\mathrm{M}-\mathrm{Osw} / \mathrm{C}$ and $\mathrm{C}-\mathrm{P} / \mathrm{C}$ models were higher with a poorer fitting quality. Moreover, the MRD value of the HEN/REA model was intermediate among all models, unlike the comparison of RMSE results.

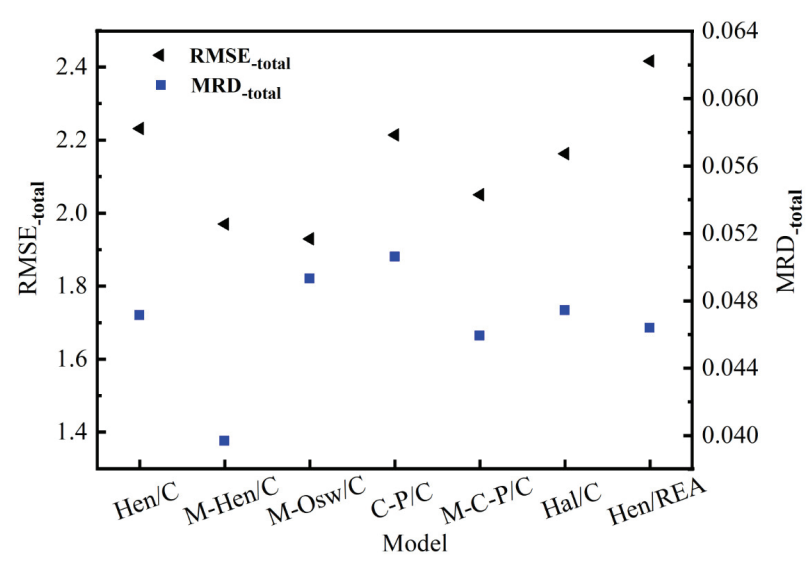

Figure 5. Comparison between RMSE and MRD values under different heat and mass transfer models.

As discussed above, the fit of the modified OSWIN model was the best with the lowest RMSE and MRD values. However, the MRD value of the M-Osw/C model was relatively high among the models in spite of its lowest RMSE value. For models of $\mathrm{M}-\mathrm{HEN} / \mathrm{C}$ and $\mathrm{C}-\mathrm{P} / \mathrm{C}$, the fitting results of the EMC model were consistent with that of the heat-mass transfer models. 

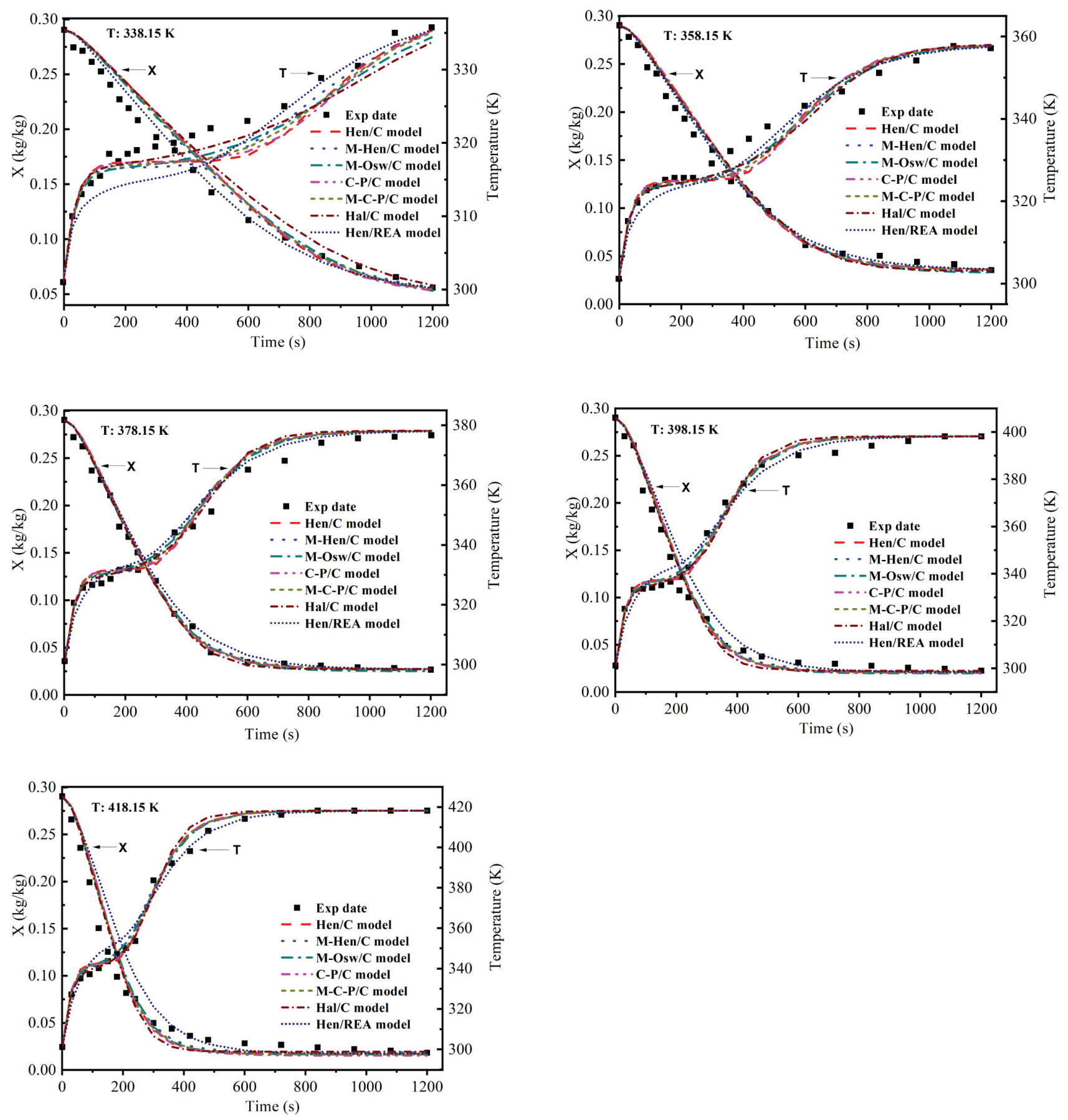

Figure 4. Comparison between experimental data and simulations given by different models.

The results indicate that the fitting results of the heat and mass transfer coefficients not only depend on the fitting quality of EMC model but are also related to those of applicability and prediction.

Figure 6 shows the comparison between $k_{m}$ and $k_{h}$ values that were optimized for numerous models. The value of $k_{m}$ calculated by HEN/REA model was significantly lower than the one for the classic models, but the value of $k_{h}$ was significantly higher than the one for the classic models. Compared with the classic models, the $\mathrm{HAL} / \mathrm{C}$ model obtained the largest $k_{m}$ value which was $0.113 \mathrm{~m}^{3} \cdot \mathrm{kg}^{-1} \cdot \mathrm{s}^{-1}$.

The value of $k_{h}$ in each model was similar in the range of $31.4 \mathrm{~W} \cdot \mathrm{kg}^{-1} \cdot \mathrm{K}^{-1}-31.7 \mathrm{~W} \cdot \mathrm{kg}^{-1} \cdot \mathrm{K}^{-1}$.
Moreover, there was no significant correlation either between the values of RMSE and $k_{m}$ or between the values of RMSE and $k_{h}$.

In order to further compare the fitting characteristics of each model, the RMSE and MRD values for various temperature conditions were analyzed. The Hen/REA model had the highest overall $\mathrm{RMSE}_{T}$ value (Figure 7) compared to the six classic models. The values of the REA model were relatively small at $358.15 \mathrm{~K}$ and $378.15 \mathrm{~K}$, which was lower than some classic models such as HEN/C, C-P/C and $\mathrm{M}-\mathrm{C}-\mathrm{P} / \mathrm{C}$ model. The RMSE of M-HEN/C model was significantly lower than that of other models at $398.15 \mathrm{~K}$. The HEN/REA model had higher $\mathrm{RMSE}_{X}$ values than the classic 


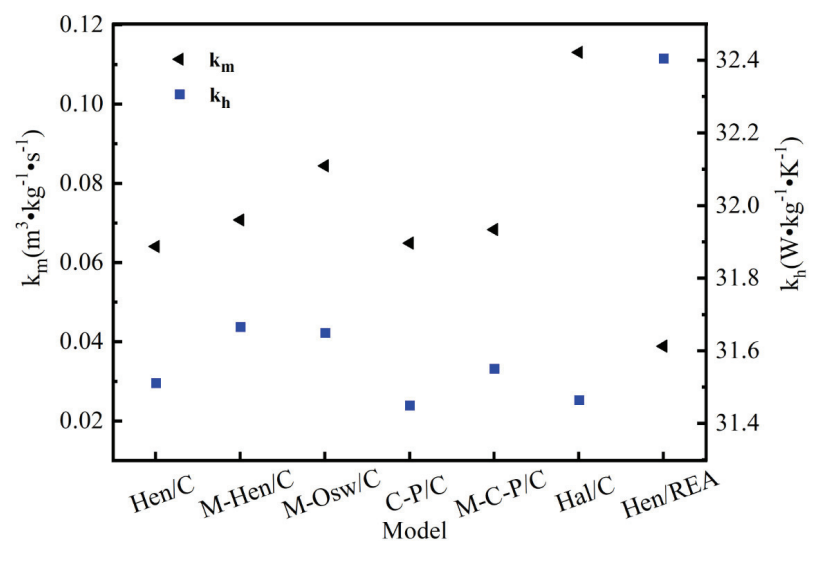

Figure 6. Coefficients of $k_{m}$ and $k_{h}$ for different heat and mass transfer models.

models. Among the classic models, the RMSE value of $\mathrm{M}-\mathrm{HEN} / \mathrm{C}$ was the lowest. The RMSE values of the HEN/REA models were significantly lower than those of the classic models at $338.15 \mathrm{~K}$ and $358.15 \mathrm{~K}$.

Overall $\mathrm{MRD}_{T}$ values (Figure 7) of HEN/REA model were higher than the ones in each classic model. Among the six classic models, the values of M-Osw/C and HAL/C models were relatively lower. The $\mathrm{MRD}_{T}$ value of the M-HEN/C model was significantly lower than in other models at $398.15 \mathrm{~K}$. Comparing the overall $\mathrm{MRD}_{X}$ values, those of the HEN/REA model were only higher than those of the M-HEN/C model. Specifically, the MRD values of HEN/REA models were obviously lower than the values of the classic models at $338.15 \mathrm{~K}$ and $358.15 \mathrm{~K}$, but higher at other temperatures. The M-HEN/C model had the lowest
MRD value at all temperatures among the classic models. The results demonstrate that the M-HEN/C model had the best fitting on moisture content.

\section{CONCLUSIONS}

Six different EMC models were introduced to calculate the driving force of mass transfer, and a mathematical model of heat and mass transfer was developed to investigate the drying of cut tobacco in a batch rotary dryer. The heat and mass transfer coefficients of the model were determined by solving a multi-objective nonlinear optimization problem using a weight factor. The simulation results show that the weight factor $r$ is an important parameter for fitting moisture content and temperature. When setting the $\mathrm{r}$ value to 0.1 , both RMSE and MRD for the whole data of moisture content and temperature almost reached their lowest values at the same time. However, the value of the mass transfer coefficient reached its maximum and the value of heat transfer coefficient almost reached its minimum. When RMSE was used as a measure of deviation, the models of $\mathrm{M}-\mathrm{Osw} / \mathrm{C}$ and $\mathrm{M}-\mathrm{HEN} / \mathrm{C}$ fitted better than the models of $\mathrm{HEN} / \mathrm{C}, \mathrm{HAL} / \mathrm{C}, \mathrm{C}-\mathrm{P} / \mathrm{C}$ and $\mathrm{M}-\mathrm{C}-\mathrm{P} / \mathrm{C}$, but the REA model was inferior to each equilibrium/classic model. When MRD was used as a measure of deviation, the $\mathrm{M}-\mathrm{HEN} / \mathrm{C}$ model was obviously superior to other equilibrium/classic models and the REA model. For all the six equilibrium/classic models the fit was better for moisture content than for temperature. This study demonstrates an understanding of heat and mass transfer in the tobacco drying process and it provides a theoretical framework to predict temperature and moisture for various drying conditions.
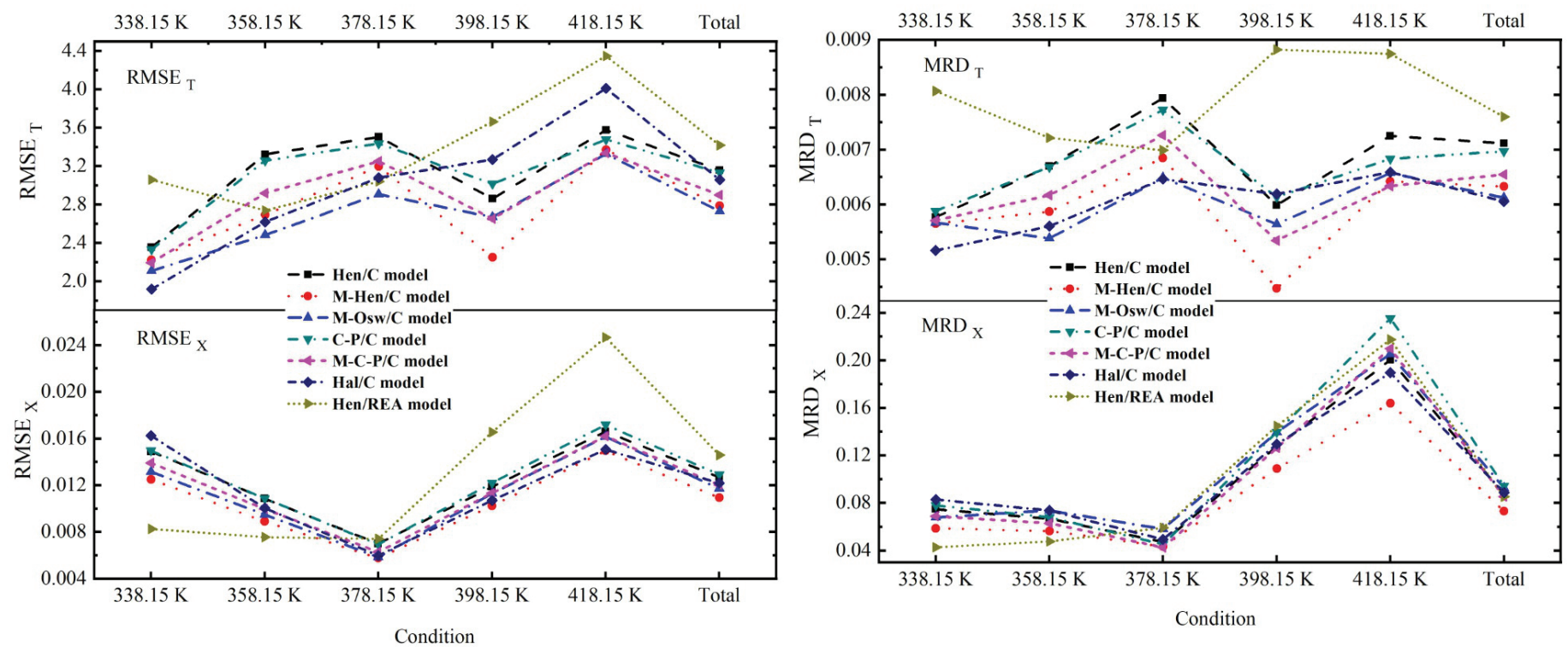

Figure 7. Comparison of RMSE and MRD values of models for various drying conditions. 


\begin{tabular}{ll}
\hline Nomenclature & \\
\hline$A, B, \mathrm{C}$ & Parameter in equilibrium model \\
$C_{p}$ & Specific heat capacity $\left(\mathrm{J} \cdot \mathrm{kg}^{-1} \cdot \mathrm{K}^{-1}\right)$ \\
$h A_{m}$ & Heat transfer coefficient $\left(\mathrm{W} \cdot \mathrm{kg}^{-1} \cdot \mathrm{K}^{-1}\right)$ \\
$h_{m} A_{m}$ & Mass transfer coefficient $\left(\mathrm{m}^{3} \cdot \mathrm{kg}^{-1} \cdot \mathrm{s}^{-1}\right)$ \\
$M$ & Molecular weight $\left(\mathrm{kg} \cdot \mathrm{mol}^{-1}\right)$ \\
$M R D$ & Mean relative deviation \\
$p$ & Vapor pressure $(\mathrm{Pa})$ \\
$R$ & Universal gas constant $\left(\mathrm{J} \cdot \mathrm{mol}^{-1} \cdot \mathrm{K}^{-1}\right)$ \\
$R H$ & Relative humidity $(1)$ \\
$\rho$ & Vapor density $\left(\mathrm{kg}{ }^{-1} \cdot \mathrm{m}^{-3}\right)$ \\
\multicolumn{1}{c}{ Subscripts } & \\
$\mathrm{b}$ & Hot gas \\
$\mathrm{cal}$ & Calculated value \\
$\mathrm{e}$ & Equilibrium zone \\
$\mathrm{exp}$ & Experimental value \\
$\mathrm{t}$ & Cut tobacco \\
$\mathrm{w}$ & water \\
\hline
\end{tabular}

\section{REFERENCES}

1. Stenström, S.: Drying of Biofuels from the Forest - A Review; Dry. Technol. 35 (2017) 1167-1181. DOI: $10.1080 / 07373937.2016 .1258571$

2. Yang, F., M. Zhang, A.S. Mujumdar, Q. Zhong, and Z. Wang: Enhancing Drying Efficiency and Product Quality Using Advanced Pretreatments and Analytical Tools - An Overview; Dry. Technol. 36 (2018) 1824-1838. DOI: 10.1080/07373937.2018.1431658

3. Lin, S.X.Q. and X.D. Chen: The Reaction Engineering Approach to Modelling the Cream and Whey Protein Concentrate Droplet Drying; Chem. Eng. Process. 46 (2007) 437-443. DOI: 10.1016/j.cep.2006.05.021

4. Patel, K.C. and X.D. Chen: Sensitivity Analysis of the Reaction Engineering Approach to Modeling Spray Drying of Whey Proteins Concentrate; Dry. Technol. 26 (2008) 1334-1343.

DOI: $10.1080 / 07373930802331019$

5. Temple, S.J. and A.J.B. van Boxtel: Equilibrium Moisture Content of Tea; J. Agric. Eng. Res. 74 (1999) 83-89. DOI: 10.1006/jaer.1999.0439

6. Li, B., W. Zhu, P. Wang, D. Lu, L. Wang, and B. Wang: Fast Drying of Cut Tobacco in Drop Tube Reactor and its Effect on Petroleum Ether Tobacco Extracts; Dry. Technol. 36 (2018) 1304-1312. DOI: $10.1080 / 07373937.2017 .1402022$

7. Rajan, K.S., K. Dhasandhan, S.N. Srivastava, and B. Pitchumani: Studies on Gas-Solid Heat Transfer During Pneumatic Conveying; Int. J. Heat Mass Transfer 51 (2008) 2801-2813.

DOI: 10.1016/j.ijheatmasstransfer.2007.09.042

8. Mabrouk, S.B., B. Khiari, and M. Sassi: Modelling of Heat and Mass Transfer in a Tunnel Dryer; Appl. Therm. Eng. 26 (2006) 2110-2118. DOI: $10.1016 /$ j.applthermaleng.2006.04.007

9. El-Mesery, H.S. and G. Mwithiga: Performance of a Convective, Infrared and Combined Infrared-Convective Heated Conveyor-Belt Dryer; J. Food Sci. Technol. 52 (2015) 2721-2730.

DOI: $10.1007 / \mathrm{s} 13197-014-1347-1$
10. Silva, D.I.S., G.F.M.V. Souza, and M.A.S. Barrozo: Heat and Mass Transfer of Fruit Residues in a Fixed Bed Dryer: Modeling and Product Quality; Dry. Technol. 37 (2019) 1321-1327. DOI: 10.1080/07373937.2018.1498509

11. Białobrzewski, I., M. Zielińska, A.S. Mujumdar, and M. Markowski: Heat and Mass Transfer During Drying of a Bed of Shrinking Particles - Simulation for Carrot Cubes Dried in a Spout-Fluidized-Bed Drier; Int. J. Heat Mass Transfer 51 (2008) 4704-4716. DOI: 10.1016/j.ijheatmasstransfer.2008.02.031

12. Silva, P.B., C.R. Duarte, and M.A.S. Barrozo: Dehydration of Acerola (Malpighia emarginata D.C.) Residue in a New Designed Rotary Dryer: Effect of Process Variables on Main Bioactive Compounds; Food Bioprod. Process. 98 (2016) 62-70. DOI: 10.1016/j.fbp.2015.12.008

13. Geng, F., Z. Yuan, Y. Yan, D. Luo, H. Wang, B. Li, and D. Xu: Numerical Simulation on Mixing Kinetics of Slender Particles in a Rotary Dryer; Powder Technol. 193 (2009) 50-58. DOI: 10.1016/j.powtec.2009.02.005

14. Geng, F., Y. Li, X. Wang, Z. Yuan, Y. Yan, and D. Luo: Simulation of Dynamic Processes on Flexible Filamentous Particles in the Transverse Section of a Rotary Dryer and its Comparison with Ideo-Imaging Experiments; Powder Technol. 207 (2011) 175-182. DOI: 10.1016/j.powtec.2010.10.027

15. Geng, F., Y. Li, L. Yuan, M. Liu, X. Wang, Z. Yuan, Y. Yan, and D. Luo: Experimental Study on the Space Time of Flexible Filamentous Particles in a Rotary Dryer; Exp. Therm. Fluid Sci. 44 (2013) 708-715. DOI: 10.1016/j.expthermflusci.2012.09.011

16. Jayas, D.S., S. Cenkowski, S. Pabis, and W.E Muir: Review of Thin-Layer Drying and Wetting Equations; Dry. Technol. 9 (1991) 551-588. DOI: $10.1080 / 07373939108916697$

17. Doymaz, İ. and O. İsmail: Drying Characteristics of Sweet Cherry; Food Bioprod. Process. 89 (2011) 31-38. DOI: 10.1016/j.fbp.2010.03.006

18. Henderson, S. M. and S. Pabis: Grain Drying Theory: 1. Temperature Affection Drying Coefficient; J. Agric. Eng. Res. 6 (1961) 169-170.

19. Menges, H.O. and C. Ertekin: Thin Layer Drying Model for Treated and Untreated Stanley Plums; Energy Convers. Manage. 47 (2006) 2337-2348. DOI: 10.1016/j.enconman.2005.11.016

20. Midilli, A., H. Kucuk, and Z. Yapar: A New Model for Single-Layer Drying; Dry. Technol. 20 (2002) 1503-1513. DOI: 10.1081/DRT-120005864

21. Hii, C.L., C.L. Law, and M. Cloke: Modeling Using a New Thin Layer Drying Model and Product Quality of Cocoa; J. Food Eng. 90 (2009) 191-198. DOI: 10.1016/j.jfoodeng.2008.06.022

22. Xu, Q. and S. Pang: Mathematical Modeling of Rotary Drying of Woody Biomass; Dry. Technol. 26 (2008) 1344-1350. DOI: 10.1080/07373930802331050

23. Gu, C., X. Zhang, B. Li, and Z. Yuan: Study on Heat and Mass Transfer of Flexible Filamentous Particles in a Rotary Dryer; Powder Technol. 267 (2014) 234-239. DOI: 10.1016/j.powtec.2014.06.059

24. Zhu, W.K., L. Wang, K. Duan, L.Y. Chen, and B. Li: 
Experimental and Numerical Investigation of the Heat and Mass Transfer for Cut Tobacco During Two-Stage Convective Drying; Dry. Technol. 33 (2015) 907-914. DOI: 10.1080/07373937.2014.997882

25. Chen, X.D., W. Pirini, and M. Ozilgen: The Reaction Engineering Approach to Modelling Drying of Thin Layer of Pulped Kiwifruit Flesh under Conditions of Small Biot Numbers; Chem. Eng. Process. 40 (2001) 311-320. DOI: 10.1016/s0255-2701(01)00108-8

26. Putranto, A., X.D. Chen, Z. Xiao, and P.A. Webley: Mathematical Modeling of Intermittent and Convective Drying of Rice and Coffee Using the Reaction Engineering Approach (REA); J. Food Eng. 105 (2011) 638-646.

DOI: 10.1016/j.jfoodeng.2011.03.036

27. Putranto, A., X.D. Chen, and W. Zhou: Modeling of Baking of Thin Layer of Cake Using the Lumped Reaction Engineering Approach (L-REA); J. Food Eng. 105 (2011) 306-311.

DOI: 10.1016/j.jfoodeng.2011.02.039

28. Li, Q., Y.F. Li, Y. Zhang, Q. Chen, H. Huang, H. Chen, Y. Lin, H. Xiao, Z. Liao, L. Che, W. Xie, and X.D. Chen: Drying Kinetics Study of Irregular Fibril Materials in a "Differential" Laboratory Rotary Dryer: Case Study for Cut Tobacco; Dry. Technol. 36 (2017) 523-536. DOI: 10.1080/07373937.2017.1341920

29. Whitman, W.G.: The Two Film Theory of Gas Absorption; Int. J. Heat Mass Transfer 5 (1962) 429-433. DOI: 10.1016/0017-9310(62)90032-7.

30. Hills, B.P. and M. Harrison: Two-Film Theory of Flavour Release from Solids; Int. J. Food Sci. Technol. 30 (1995) 425-436. DOI: 10.1111/j.1365-2621.1995.tb01390.x

31. Smith, J.M., H.C. Van Ness, and M.M. Abbott: Introduction to Chemical Engineering Thermodynamics; $7^{\text {th }}$ Edition, McGraw-Hill Education, NY, USA, 2004.

32. Henderson, S.M.: A Basic Concept of Equilibrium Moisture Content; Agric. Eng. 33 (1952) 29-32.

33. Thompson, T.L., R.M. Peart, and G.H. Foster: Mathematical Simulation of Corn Drying - A New Model; Trans. ASAE 24 (1968) 582-586. Available at: https://www.ars.usda.gov/ARSUserFiles/30200525/ 34MathematicalSimulationofCornDrying.pdf (accessed November 2020)

34. Chen, C.C. and R.V. Morey: Comparison of Four EMC/ERH Equations; Trans. ASAE 32 (1989) 983-990. Available at: https://elibrary.asabe.org (accessed November 2020)

35. Chung, D.S. and H.B. Pfost: Adsorption and Desorption of Water Vapor by Cereal Grains and Their Products. Part II: Development of the General Isotherm Equation; Trans. ASAE 10 (1067) 552-555. Available at: https://elibrary.asabe.org (accessed November 2020)
36. Pfost, H., S.G. Maurer, D. Chung, and G. Milliken: Summarizing and Reporting Equilibrium Moisture Data for Grains; ASAE Paper No. 76-3520, St. Joseph, MI, USA, 1976.

37. Halsey, G.: Physical Adsorption on Non-Uniform Surfaces; J. Chem. Phys 16 (1948) 931-937. DOI: $10.1063 / 1.1746689$

38. Yaws, C.L.: Chemical Properties Handbook; McGrawHill Education, NY, USA, 1999.

39. Linstrom, P.J. and W.G. Mallard: Nist Chemistry WebBook, Nist Standard Reference Database Number 69, National Institute of Standards and Technology, Gaithersburg, MD, USA, 2005. Available at: https://webbook.nist.gov/chemistry/

40. Zhu, L., X. Qin, Z. Yuan, Y. Yan, D. Luo, and B. Li: Heat and Mass Transfer Characteristics of Filamentous Particles in Transverse Section of Rotary Dryer; Journal of Southeast University, Natural Science Edition, 44 (2014) 756-763.

DOI: 10.3969/j.issn.1001-0505.2014.04.014

41. Atashkari, K., N. Nariman-Zadeh, A. Pilechi, A. Jamali, and X. Yao: Thermodynamic Pareto Optimization of Turbojet Engines Using Multi-Objective Genetic Algorithms: Int. J. Thermal Sci. 44 (2005) 1061-1071. DOI: 10.1016/j.ijthermalsci.2005.03.016.

42. Sarkar, D. and J.M. Modak: Pareto-Optimal Solutions for Multi-Objective Optimization of Fed-Batch Bioreactors Using Nondominated Sorting Genetic Algorithm; Chem. Eng. Sci. 60 (2005) 481-492. DOI: $10.1016 /$ j.ces.2004.07.130.

43. Sun, D.W.: Comparison and Selection of EMC/ERH Isotherm Equations for Rice; J. Stored Prod. Res. 35 (1999) 249-264. DOI: 10.1016/s0022-474x(99)00009-0.

Corresponding author:

Le Wang, Ph.D.

Zhengzhou Tobacco Research Institute of CNTC

Zhengzhou 450001

P.R. China

E-mail:wangleztri@outlook.com 